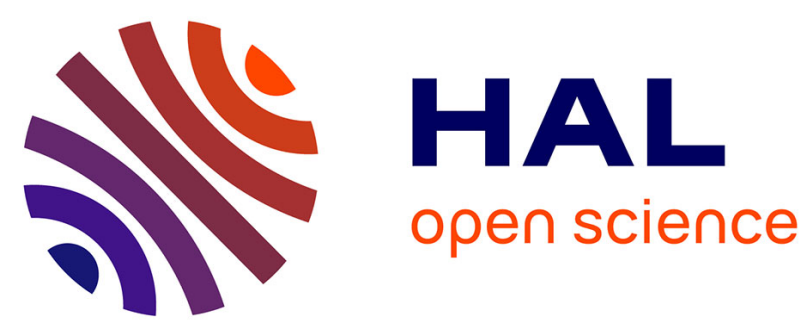

\title{
Conversion from laparoscopic to open colonic cancer resection - associated factors and their influence on long-term oncological outcome
}

\author{
H. Ptok, R. Kube, U. Schmidt, F. Köckerling, I. Gastinger, H. Lippert
}

\section{- To cite this version:}

H. Ptok, R. Kube, U. Schmidt, F. Köckerling, I. Gastinger, et al.. Conversion from laparoscopic to open colonic cancer resection - associated factors and their influence on long-term oncological outcome. EJSO - European Journal of Surgical Oncology, 2009, 35 (12), pp.1273. 10.1016/j.ejso.2009.06.006 . hal-00556316

\section{HAL Id: hal-00556316 https://hal.science/hal-00556316}

Submitted on 16 Jan 2011

HAL is a multi-disciplinary open access archive for the deposit and dissemination of scientific research documents, whether they are published or not. The documents may come from teaching and research institutions in France or abroad, or from public or private research centers.
L'archive ouverte pluridisciplinaire HAL, est destinée au dépôt et à la diffusion de documents scientifiques de niveau recherche, publiés ou non, émanant des établissements d'enseignement et de recherche français ou étrangers, des laboratoires publics ou privés. 


\section{Accepted Manuscript}

Title: Conversion from laparoscopic to open colonic cancer resection - associated factors and their influence on long-term oncological outcome

Authors: H. Ptok, R. Kube, U. Schmidt, F. Köckerling, I. Gastinger, H. Lippert

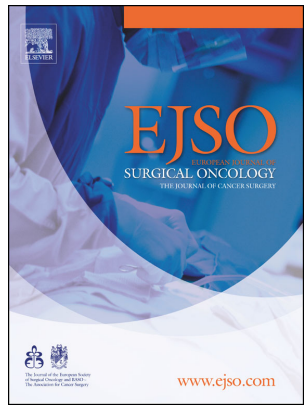

PII:

S0748-7983(09)00198-X

DOI:

10.1016/j.ejso.2009.06.006

Reference: YEJSO 2850

To appear in: European Journal of Surgical Oncology

Accepted Date: 11 June 2009

Please cite this article as: Ptok H, Kube R, Schmidt U, Köckerling F, Gastinger I, Lippert H. Conversion from laparoscopic to open colonic cancer resection - associated factors and their influence on long-term oncological outcome, European Journal of Surgical Oncology (2009), doi: 10.1016/j.ejso.2009.06.006

This is a PDF file of an unedited manuscript that has been accepted for publication. As a service to our customers we are providing this early version of the manuscript. The manuscript will undergo copyediting, typesetting, and review of the resulting proof before it is published in its final form. Please note that during the production process errors may be discovered which could affect the content, and all legal disclaimers that apply to the journal pertain. 


\section{Conversion from laparoscopic to open colonic cancer resection -} associated factors and their influence on long-term oncological outcome..

Running title: Outcome of converted colon resection

H. Ptok, MD ${ }^{1,4}$, R. Kube, MD ${ }^{1,4}$, U. Schmidt ${ }^{5}$, F. Köckerling, $\mathrm{PhD}^{1,3}$, I. Gastinger, $\mathrm{PhD}^{1,4}$, H. Lippert, PhD ${ }^{1,2}$; the “Colon/Rectum Carcinoma (Primary Tumor)” Study Group

${ }^{1}$ Institute of Quality Assurance in Operative Medicine, University Hospital of the Otto von Guericke University of Magdeburg, Leipziger Str. 44, 39120 Magdeburg, Germany

${ }^{2}$ Department of General, Visceral and Vascular Surgery, University Hospital of the Otto von Guericke University of Magdeburg, Leipziger Straße 44, 39120 Magdeburg, Germany

${ }^{3}$ Department of Surgery and Minimally Invasive Surgery, Hanover Hospital Resenbeckstrasse 15 (Siloah), 30449 Hanover, Germany

4 Department of Surgery, Carl Thiem Hospital Cottbus, Thiemstraße 111, 03048 Cottbus, Germany

${ }^{5}$ StatConsult, Goethestraße 1, 39120 Magdeburg

\section{Corresponding author:}

Henry Ptok, M.D.

Institute of Quality Assurance in Operative Medicine University Hospital Magdeburg

Leipziger Str. 44

39120 Magdeburg, Germany

Telephone and telefax: +49 - 391 - 6714068

E-mail: henry.ptok@med.ovgu.de

Word count: Manuscript: 2999

Abstract: 


\begin{abstract}
Purpose: Comparisons of open and laparoscopic colon cancer resection have shown that laparoscopy offers an oncologically safe option. However, there are no data on long-term influence of converted resection, despite conversion rates of up to $30 \%$ and the general observation that short-term outcome is significantly worsened. The aim was to compare the long-term results of primary open resection (OR), purely laparoscopic resection (LR-p) and converted resection (LR-c).

Methods: In a prospective study at 282 German hospitals demographic, tumor- and treatment-related data and disease-free survival were compared in the three groups.

Results: 8015 of 8307 patients with OR, 280 of 290 patients with LR-p and 55 of 56 patients with LR-c were followed for 39.5 months (median). Overall, no statistically significant differences were seen for five-year DFS (74.8\%, 81.3\% and 65.6\%). However, for patients in stage II with conversion, the five-year DFS was significantly poorer (43.3\%) than for OR (80.5\%; $p=0.003)$ and LR-p patients (92.5\%; $p=0.001)$. For stages I and III no differences were observed.

Conclusion: Conversion of laparoscopic colon cancer resection worsens DFS in locally advanced stage II carcinoma. There is a need to reduce the conversion rate by adequate patient selection for laparoscopic resection by experienced surgeons.
\end{abstract}

Key words: Colon cancer - laparoscopic resection - conversion - oncological results disease-free survival. 


\section{Introduction}

Prospective, randomized studies and meta-analyses in colon carcinoma have shown oncological safety and equivalent long-term oncological results of laparoscopic resection to those of open resection [1, 2]. In colon carcinoma, laparoscopic resection has several advantageous aspects that are of secondary importance from the oncological point of view; they include reduced post-operative pain, earlier bowel movements, quicker dietary normalization, shorter hospital stay, reduced blood loss and less scarring [1, 3-5].

Laparoscopic resection of colo-rectal carcinoma demands considerable technical experience in the use of minimally invasive methods, and one factor that depends directly upon this is the conversion rate. An analysis by Morino et al. [6] has shown that in the case of rectal carcinoma a justifiably low conversion rate of below $15 \%$ is reached only after some 100 laparoscopic resections. Likewise Marusch et al. [7] report a significantly lower conversion rate in hospitals that conduct more than 100 laparoscopic resections per year and Kuhry et al. [8] were able to show, that the conversion rate depends significantly upon the hospital volume. Results of other unicentric and multicentric trials have shown a wide range of conversion rates, from below 5\% to above $40 \%$ [2, 9-15], dependent upon the experience at the site and the selection of patients. In the study populations of the CLASSIC trial, the COST trial and the COLOR trial $[1,3,4]$, the conversion rates for elective laparoscopic colon carcinoma resection were respectively $17 \%, 21 \%$ and $17 \%$.

Regarding the influence of the conversion upon the success of treatment, the only data currently available are for the early post-operative outcome. Belizon et al. [16] investigated the influence of conversion upon the early post-operative events following laparoscopic resection of benign, inflamed and malignant colon carcinoma. A match-paired comparison between patients after converted laparoscopy versus primary open resection showed a significantly higher morbidity for the conversion group, particularly in respect of wound infection, of anastomotic leakage and incisional herniation. In the CLASSIC trial, conversion 
was also found to be associated with a higher rate of wound infection and an increased frequency of pulmonary infections, in comparison with open and purely laparoscopic resections. However, a higher rate of anastomotic leakage was not seen [3].

To date, no results have been published dealing with oncologically long-term outcome after conversion from laparoscopic to open resection. Therefore, the present analysis was conducted in order to investigate the long-term oncological results of converted colon carcinoma resection compared with open resection. Only if the long-term results after conversion are not significantly worse than those of open resection the conversion rates mentioned above can be justified. Otherwise, the selection criteria must be defined in such a way that patients with a high risk of conversion are allocated to primary open resection. 


\section{Methods}

Study

Within the multicentre observation study “Colon/Rectal Carcinoma (Primary Tumour)”, from 1.1.2000 to 31.12.2004 data of 30,453 patients with colon carcinoma were acquired prospectively by the "Institute for Quality Assurance in Operative Medicine” at the Otto-vonGuericke University of Magdeburg, Germany. In this observational study, patients are included who have been operated on for carcinoma of the colon or rectum. The participation of hospitals in the study is voluntary, and it helps them to monitor the quality of their treatment and to compare it with that at other centres. The data acquired are assessed for each hospital and for the entire study, and the results are provided to the participating hospitals in annual reports. Each year, data from approximately 6000 colon-cancer patients and 3000 rectal-cancer patients are recorded in the study. To record information about the patient, the tumor, the operation, the course of disease from the operation up to discharge from hospital, and histopathological information a standardized questionnaire was completed at the hospital where the patient was treated. A second questionnaire was completed by the patient's own doctor or, where appropriate, by the hospital; this include last contact with the patient, life status or cause of death (tumor-related, tumor-independent), any local recurrence, any distal metastasis, and as appropriate the time of recurrence and the method of detection (biopsy, endoscopy, imaging). A detailed description of the study design and monitoring has already been published [17].

The study was conducted according to the Declaration of Helsinki for Biomedical Research. Participation was voluntary, evaluation was based on anonymous data, and the study involved observation only - i.e., it had no influence upon the choice or course of therapy. For these reasons, an Ethics Committee vote was not necessary. All patients gave their written consent to the collection and the anonymous evaluation of their data. The primary data and the end 
results represent the standard of patient care in clinical routine and cover the entire spectrum of institutions from hospitals providing basic care to university hospitals.

\section{Analysis}

Study patients who were operated on for colon carcinoma in UICC (Union Internationale Contre le Cancer) stages I to III and had undergone elective operation, with curative intent, for confirmed or suspected carcinoma were included in the present analysis. Patients operated upon without previous suspicion of the carcinoma, and those who underwent emergency operation, were not included. Furthermore only patients recorded in the period 1.1.2000 to 31.12.2002 were considered, in order to leave a sufficiently long post-operative follow-up interval.

To determine the influence of the conversion from laparoscopic to open resection upon the long-term oncological outcome compared with primary open resection, the patients were classified into three groups: (i) patients with primary open resection (OR), (ii) those with purely laparoscopic resection (LR-p), and (iii) those with resection converted from the laparoscopic to the open approach (LR-c). For some analyses, the latter two groups were pooled (laparoscopy, intention-to-treat; LR-ITT). The choice to perform primary open or primary laparoscopic resection was made by the hospital surgeon responsible for the case, according to the usual criteria in the hospital; this decision was not influenced in any way by the centre's participation in this observational study. The groups were compared in respect of demographic data, tumour location, pT category, pN category, number of lymph nodes sampled, UICC stage, duration of operation, intra-operative and post-operative morbidity and mortality.

The assessment of the long-term oncological outcome was conducted on the basis of diseasefree survival (DFS) and overall survival (OS). 


\section{Statistics}

Data processing was performed with the statistical program SPSS 12.0. Continuous variables were compared between groups by using Student's $t$ test (two-group comparison) or univariate variance analysis (one-way-ANOVA; 3-group comparison) and results were expressed as means with associated confidence intervals. Categorical variables were compared by using the $\chi^{2}$ test. The univariate analysis of DFS for the various groups was performed by the KaplanMeier method. DFS and OS rates between group were compared by log-rank analysis. In all tests, differences between the groups were considered significant when a two-sided test yielded $p<0.05$. 


\section{Results}

From 2000 to 2002, a total of 13,574 patients were treated by curative resection of UICC stage I-III colon carcinoma in 282 hospitals. A total of 8653 patients were eligible for analysis. In 8307 patients a primary open resection was performed (OR). In another 346 patients the resection was commenced laparoscopically (LR-ITT). For 56 of the 346 patients for whom colon resection was commenced laparoscopically, the operation was converted to an open one. This corresponds to a conversion rate of $16 \%$. In Table 1 the tumor locations of the OR group, the LR-ITT group and the LR-c group are compared: $89 \%$ of the planned laparoscopies were for patients with tumours in the caecum and the ascending or sigmoid colon. For tumours in the remaining colon sections, laparoscopic resection was commenced relatively infrequently compared with primary open resection. Figure 1 shows the conversion rates after laparoscopically commenced resection, broken down by tumour location. Conversion rates above average were found for tumours in the transverse colon and in the region of the splenic flexure. Thus, this distribution by tumour location is approximately the converse of the distribution of laparoscopic resections.

\section{Reasons for conversion}

In Table 2 the frequencies of reasons for conversion are given, for the entire collective of 56 patients with conversion and for each UICC stage.

\section{Comparison of treatment groups}

Table 3 presents demographic data and early post-operative morbidity rates for the patients in the various treatment groups (OR, LR-ITT, LR-p and LR-c). The results of statistical testing are shown for comparisons (i) between the OR and LR-ITT groups and (ii) between the OR and LR-c groups. The comparison of the OR and LR-ITT groups shows that patients for whom the laparoscopic technique was chosen were significantly younger, suffered from 
significantly fewer co-morbidities (ASA score) and, above all, showed significantly more favorable tumour characteristics (pT category, UICC stage). In respect of early post-operative morbidity and mortality no significant differences were seen.

The comparison between OR and LR-c patients shows no differences between these groups in respect of demographic or disease variables. Significant difference was seen for the duration of the operation. In the comparison of early post-operative outcome no significant differences were found, even though the overall post-operative morbidity in the LR-c group was noticeably higher than that in the OR group.

\section{Comparison of long-term oncological results}

For the comparison of long-term oncological results, follow-up information was available for 8015 of the 8307 OR patients, for 280 of the 290 LR-p patients and for 55 of the 56 LR-c patients. The median follow-up time was 39.5 months overall (OR, 39.5 m; , LR-p, 38.7 m; LR-c, $39.1 \mathrm{~m} ; p=0.352)$.

Five-year DFS and five-year OS rates for the OR and LR-ITT groups in all UICC stages did not differ significantly: DFS, 74.8\% vs. 78.9\%, $p=0.267$ (Figure 2A); OS, 70.1\% vs. 79.9\%, $p=0.071$. Similarly, the comparison of five-year DFS and OS between the three groups (OR, LR-p, LR-c) showed no significant differences: DSF, $74.8 \%$ vs. $81.3 \%$ vs. $65.6 \%$ (Figure 2B); OS, $70.1 \%$ vs. $81.8 \%$ vs. $67.9 \%$.

\section{Comparison of DFS stratified by UICC stage}

The comparisons of five-year DFS for patients in UICC stage I did not show any significant difference. $86.5 \%$ of the patients after open resection and $90.0 \%$ after laparoscopically commenced resection survived for five years disease free $(p=0.443)$.

Even when the laparoscopically resected patient groups were considered separately, no significant differences can be found. 5-y-DFS was achieved for $89.7 \%$ of LR-p patients, 
92.3\% of LR-c patients and $86.5 \%$ of OR patients (LR-c versus LR-p, $p=0.982$; LR-c versus OR, $p=0.748$; LR-p versus OR, $p=0.483)$.

In UICC stage II, the comparison of the OR group with the LR-ITT group showed no statistically significant difference in the 5 -y-DFS rate $(80.5 \%$ versus $82.9 \%$; $p=0.988$; Figure 3A).

When the comparison in UICC stage II was performed for the LR-p and LR-c groups separately, it was found that patients with conversion had a significantly worse outcome (43.3\%) compared with those whose laparoscopic resection was not converted (92.5\%; $p=0.001)$ and with patients with primary open resection $(80.5 \% ; p=0.004)$. However, no significant difference in 5-y-DFS was seen between the LR-p and OR patients $(p=0.158$; Figure 3B).

The analysis of DFS for the OR, LR-ITT, LR-p and LR-c patients within UICC stage III showed 5-y-DFS rates of respectively 60.4\%, 63.0\%, 63.6\% und 52.2\%. In this comparison, there was no significant difference between the OR and LR-ITT patients ( $p=0.932$ ) or among the OR, LR-p and LR-c groups (LR-c versus LR-p, $p=0.985$; LR-c versus OR, $p=0.986$; LR-p versus OR, $p=0.933)$. 


\section{Discussion}

There is today no doubt of the feasibility of laparoscopic resection of colon carcinoma and its equivalence to open resection in terms of safety and oncological results $[1,3,4,18,19]$. Likewise, long-term observations - including those presented in this paper - have shown that the long-term outcome of curative resection in the ITT laparoscopy group is comparable with the corresponding rate for primary open resection $[1,2,20]$.

Data on the influence of conversion from laparoscopic to open resection are restricted to early post-operative results. Thus, in the CLASSIC trial [3], and in the unicentric analysis by Belizon et al. [16], a higher post-operative morbidity and a longer hospital stay was found for patients with conversion compared to patients with open resection. However, not all authors agree that conversion has such an influence [15]. Likewise, the present survey showed an increased but not statistically significant post-operative morbidity after conversion compared to the open resection.

\section{Influence of conversion on long-term results}

In contrast, the literature currently contains no data on the influence of conversion upon longterm oncological outcome. The analysis presented here compared this outcome for patients with converted laparoscopic resection with the corresponding outcome for patients with primary open resection. Based upon the premise that even if laparoscopic resection is advantageous in terms of lower immunosuppression [21, 22, 23], in the case of conversion the results should not be worse than those of primary open resection. If the results after conversion were less favorable than that of primary resection, the conversion group must be described as a high-risk population, which in turn would lead to the demand for an improvement of pre-operative selection of patients for laparoscopic resection with low risk of conversion. 
In the presented analysis, the comparison of the patients with colon carcinoma in UICC stages I-III undergoing primary open resection vs. laparoscopic resection (ITT) shows that the patients selected for laparoscopy did not differ from the others in respect of demographic data, but they had significantly more favourable $\mathrm{pT}$ categories, and correspondingly more favourable UICC stages. Furthermore, for the LR-ITT patients a selection in respect of tumour location was observed, with a clear majority of sigma carcinomas, in comparison with the primary open resected group. The comparison of conversion group and primary open resection group did not show any differences in respect of demographic data, pT category or UICC stage.

In the comparison of long-term oncological outcome presented here between UICC stage II patients with primary open resection and those with converted laparoscopic resection, it emerges that the conversion has a deleterious impact upon DFS. For UICC stage I tumors the conversion has no demonstrable negative prognostic effect on DFS, as was also the case for UICC stage III tumors.

\section{Conversion in UICC stage II patients}

The comparison of reasons for conversion among the LR-c patients in UICC stage II with the corresponding reasons in stages I and III shows that the reasons 'unclear anatomy', 'local expansion of the tumor' and 'intra-operative tumor perforation' were more common in stage II. As shown in an analysis by Leung et al. [2], the difficulty of operating close to a colon carcinoma is associated with a raised oncological risk of spreading tumor cells.

The results presented here on the influence of the conversion upon the long-term oncological outcome following laparoscopically commenced resection of colon carcinoma show that a decisive contribution to this is made by the selection of patients for planned laparoscopy. Above all, the tumour size and tumour location - influence the probability of conversion and thus the outcome. Even though the comparison of long-term results after primary open 
resection vis-á-vis planned laparoscopic resection was not the central feature of this comparison, the results nevertheless show that DFS is comparable between these operative techniques, both overall and within each UICC stage.

\section{Conversion, caseload and learning curve}

Tekkis et al. [24] have produced a model for the prediction of conversion in colon resection, done on the basis of a broad spectrum of colon disorders. Within the group with malignomas, the highest conversion rate was found for T4 tumors. Regarding the experience of the surgeon, a shallow learning curve has been reported. Tekkis et al. [25] have also evaluated the course of the learning curve in a comparison of right-side and left-side laparoscopic colon resections. Beside a lower conversion rate for right-side compared with left-side laparoscopies, these authors found that the learning curve for the right hemicolon reached a plateau after 55 laparoscopic resections, and for the left hemicolon reached a plateau after 62 resections. Other authors also see a shallow learning curve, with a plateau after $40-80$ laparoscopic resections [26, 27].

In summary, the analysis presented here shows that a consideration of the long-term oncological result of laparoscopic resection (ITT), is comparable to that of open resection. However, the conversion from laparoscopic to open resection in cases of locally advanced tumor (UICC stage II) results in a worsening of the prognosis. In consequence, selection of patients for laparoscopic resection must take account of these factors, including the experience of the operating surgeon, with the aim of reducing the incidence of negative, oncologically relevant intra-operative events and thus of decreasing the frequency of conversion.

\section{Limitations}


The results of this study must be interpreted with care, on account both of the small conversion group and of the nature of the study (observation study, evidence level III). It is regrettable that at present no results from randomized studies or from trials with a larger sample size are available for comparison. Limitations of these results are the absence of information on the time point of conversion and the oncologically limited possible statements regarding the influence of the reasons for the conversion upon the oncological outcome. No conclusions can be drawn about the isolated influence of the conversion upon long-term results, because of the interference between conversion and the incidence of intra-operative complications. A multivariate comparison of long-term results between the LR-c and the OR patients was not performed, because of the above-mentioned interference between intraoperative complications and conversion, the non-significant, but appreciable differences between these groups in respect of demographic and tumor-related variables, the relatively favorable tumor location for the LR-c patients in UICC stage II and the small number of patients in the conversion group.

However, a worsening of the results by the conversion alone seems unlikely; rather, the problem appears to lie in oncologically relevant intra-operative events that lead to conversion, and effort should be made to reduce the frequency of these by early conversion in the case of laparoscopically unresectable tumours. 


\section{Conflict of interest statement:}

All authors disclose any financial and personal relationships with other people or organisations that influence the presented work.

\section{Sources of support:}

The authors conducted this research within the terms of their employment. Participating hospitals made a per-patient contribution to cover direct costs. There is no further financial support to state. 


\section{References}

[1] The Clinical Outcomes of Surgical Therapy Study Group. A comparision of laparoscopically assisted and open colectomy for colon cancer. N Engl J Med 2004; 350: 2050 - 9.

[2] Leung KL, Kwok SP, Lam SC, et al. Laparoscopic resection of rectosigmoid carcinoma: prospective randomized trial. Lancet 2004; 363: 1187 - 92.

[3] Guillou PJ, Quirke P, Thorpe H, et al.; for the MRC CLASICC trial group. Short-term endpoints of conventional versus laparoscopic assisted surgery in patients with colorectal cancer (MRC CLASICC trial): multicentre, randomized controlled trial. Lancet 2005; 365: $1718-26$.

[4] The Colon Cancer Laparoscopic or Open Resection Study Group. Laparoscopic surgery versus open surgery for colon cancer: Short-term outcomes of a randomized trial. Lancet 2005; 6: 477 - 84.

[5] Schwenk W, Haase O, Neudecker J, Müller JM. Short term benefits for laparoscopic colorectal resection. Cochrane Database Syst Rev 2005; CD003145. DOI: 10.1002/14651858.

[6] Morino M, Allaix ME, Giraudo G, Corno F, Garrone C. Laparoscopic versus open surgery for extraperitoneal rectal cancer. A prospective comparative study. Surg Endosc 2005; 19: $1460-7$.

[7] Marusch F, Gastinger I, Schneider C, et al. Importance of conversion for results obtained with laparoscopic colorectal surgery. Dis Colon Rectum 2001; 44: 207 - 14.

[8] Kuhry E, Bonjer HJ, Haglind E, et al.; COLOR Study Group. Impact of hospital case volume on short-term outcome after laparoscopic operation for colonic cancer. Surg Endosc 2005; 19: 687 - 92.

[9] Reichenbach DJ, Tackett AD, Harris J, et al. Laparoscopic colon resection early in the learning curve. What is the appropriate setting? Ann Surg 2006; 243: 730 - 7. 
[10] Lezoche E, Guerrieri M, De Sanctis A, et al. Long-term results of laparoscopic versus open colorectal resections for cancer in 235 patients with a minimum follow-up of 5 years. Surg Endosc 2006; 20: 546 - 53.

[11] Leroy J, Ananian P, Rubino F, Claudon B, Mutter D, Marescaux J. The impact of obesity on technical feasibility and postoperative outcomes of laparoscopic left colectomy. Ann Surg 2005; 241: 69 - 76.

[12] Senagore AJ, Delaney CP. A critical analysis of laparoscopic colectomy at a single institution: lessons learned after 1000 cases. Am J Surg 2006; 191: 377 - 80.

[13] Kaiser AM, Kang JC, Chan LS, Vukasin P, Beart RW Jr. Laparoscopic assisted vs. open colectomy for colon cancer: a prospective randomized trial. J Laparoendosc Adv Surg Tech A 2004; 14: 329 - 34.

[14] Kitano S, Kitajima M, Konishi F, Kondo H, Satomi S, Shimizu N; Japanese Laparoscopic Surgery Study Group. A multicenter study on laparoscopic surgery for colorectal cancer in Japan. Surg Endosc 2006; 20: 1348 - 52.

[15] Casillas S, Delaney CP, Senagore AJ, Brady K, Fazio VW. Does conversion of a laparoscopic colectomy adversely affect patient outcome? Dis Colon Rectum 2004; 47: $1680-5$.

[16] Belizon A, Sardinha CT, Sher ME. Converted laparoscopic colectomy. What are the consequences? Surg Endosc 2006; 20: 947 - 51.

[17] Marusch F, Koch A, Schmidt U, et al. Importance of rectal extirpation for the therapy concept of low rectal cancers. Chirurg 2003; 74: 341-52.

[18] Abraham NS, Young JM, Solomon MJ. Meta-analysis of short-term outcomes after laparoscopic resection for colorectal cancer. Br J Surg 2004; 91: 1111 - 24.

[19] Veldkamp R, Gholghesaei M, Bonjer HJ, et al. Laparoscopic resection of colon cancer. Consensus of European Association of Endoscopic Surgery (EAES). Surg Endosc 2004; 18: $1163-85$. 
[20] Liang JT, Huang KC, Lai HS, Lee PH, Jeng YM. Oncologic results of laparoscopic versus conventional open surgery for stage II or III left-sided colon cancers: a randomized controlled trial. Ann Surg Oncol 2007; 14: 109 - 17.

[21] Braga M, Vignali A, Zuliani W, et al. Metabolic and functional results after laparoscopic colorectal surgery: a randomized, controlled trial. Dis Colon Rectum 2002; 45: $1070-7$.

[22] Tang CL, Eu KW, Tai BC, Soh JG, MacHin D, Seow-Choen F. Randomized clinical trial of the effect of open versus laparoscopically assisted colectomy on systemic immunity in patients with colorectal cancer. Br J Surg 2001; 88: 801 - 7.

[23] Belizon A, Balik E, Feingold DL, et al. Major abdominal surgery increases plasma levels of vascular endothelial growth factor. Open more so than minimally invasive methods. Ann Surg 2006; 244: 792 - 8 .

[24] Tekkis PP, Senagore AJ, Delaney CP. Conversion rates in laparoscopic colorectal surgery. A predictive model with 1253 patients. Surg Endosc 2005; 19: 47 - 54.

[25] Tekkis PP, Senagore AJ, Delaney CP, Fazio VW. Evaluation of the learning curve in laparoscopic colorectal surgery. Ann Surg 2005; 242: 83 - 91.

[26] Bennett CL, Stryker SJ, Ferreira MR, Adams J, Beart RW Jr. The learning curve for laparoscopic colorectal surgery: preliminary results from a prospective analysis of 1194 laparoscopic-assisted colectomies. Arch Surg 1997; 132: 41 - 4.

[27] Dincler S, Koller MT, Steurer J, Bachmann LM, Christen D, Buchmann P. Multidimensional analysis of learning curves in laparoscopic sigmoid resection: eightyear results. Dis Colon Rectum 2003; 46: 1371 - 8 . 
Table 1

Distribution of open, laparoscopic (ITT) and converted laparoscopic surgery according to the colon carcinoma location.

\begin{tabular}{|c|c|c|c|c|c|c|}
\hline & $\begin{array}{l}\text { Caecum and } \\
\text { ascending } \\
\text { colon }\end{array}$ & $\begin{array}{l}\text { Hepatic } \\
\text { flexure }\end{array}$ & $\begin{array}{c}\text { Transverse } \\
\text { colon }\end{array}$ & $\begin{array}{l}\text { Splenic } \\
\text { flexure }\end{array}$ & $\begin{array}{l}\text { Descending } \\
\text { colon }\end{array}$ & $\begin{array}{l}\text { Sigmoid } \\
\text { colon }\end{array}$ \\
\hline $\begin{array}{l}\text { Open resection } \\
N=8307\end{array}$ & 2691 & 606 & 598 & 382 & 476 & 3554 \\
\hline $\begin{array}{l}\text { Laparoscopic } \\
\text { resection (ITT) } \\
N=346\end{array}$ & 63 & 9 & 8 & 8 & 13 & 245 \\
\hline $\begin{array}{l}\text { Laparoscopic } \\
\text { resection with } \\
\text { conversion } \\
N=56\end{array}$ & 8 & 1 & 2 & & 2 & 40 \\
\hline
\end{tabular}


Table 2

Absolute and relative frequencies of reasons for conversion, total and stratified by UICC stage.

\begin{tabular}{|c|c|c|c|c|}
\hline & Frequency & & UICC stage & \\
\hline Reason for conversion & $\begin{array}{c}\text { Absolute } \\
(N)\end{array}$ & $\begin{array}{c}\mathrm{I} \\
(N)\end{array}$ & $\begin{array}{l}\text { II } \\
(N)\end{array}$ & $\begin{array}{l}\text { III } \\
(N)\end{array}$ \\
\hline Adhesion & 9 & 5 & 2 & 2 \\
\hline Ureter injury & 1 & - & 1 & - \\
\hline Intestinal injury (distal to tumor) & 4 & 3 & 1 & - \\
\hline Problems with the capnoperitoneum & 3 & - & 2 & 1 \\
\hline Tumor location & 3 & 1 & - & 2 \\
\hline Unclear anatomy & 8 & 2 & 4 & 2 \\
\hline Injury to blood vessel & 2 & - & 2 & - \\
\hline Size or extent of tumor & 9 & - & 5 & 4 \\
\hline Intra-operative tumor perforation & 3 & 1 & 2 & - \\
\hline Other & 14 & 7 & 2 & 5 \\
\hline Total & 56 & 19 & 21 & 16 \\
\hline
\end{tabular}


Table 3

Survey of the patient groups; comparison of epidemiological and tumour-specific variables and post-operative outcome

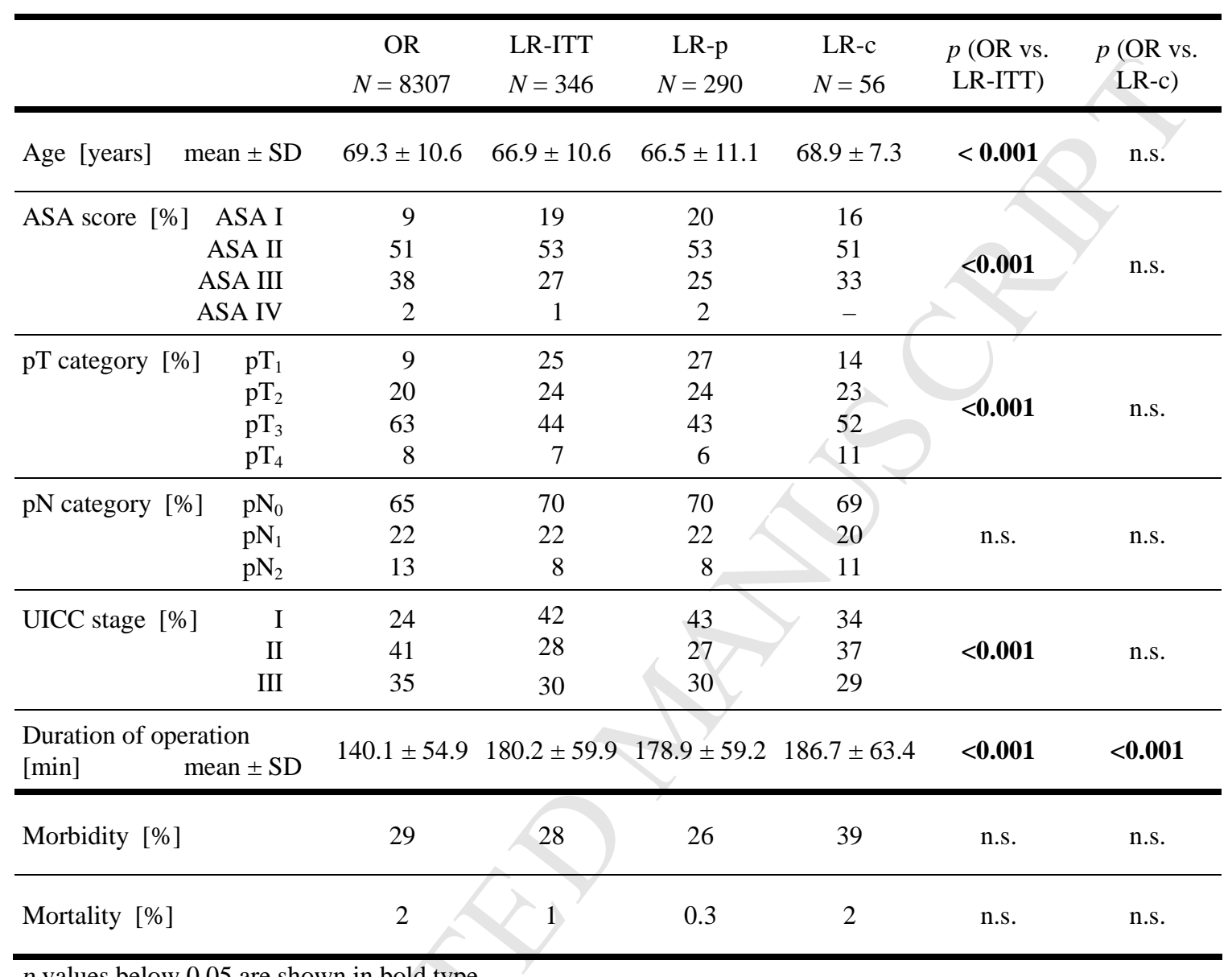

$p$ values below 0.05 are shown in bold type. 


\section{Table 4}

Comparison of pT3/pT4 distribution and distribution of tumour location between OR patients, LR-p patients and LR-c patients within UICC stage II

\begin{tabular}{|c|c|c|c|c|}
\hline & $\begin{array}{c}\text { OR } \\
(N=3396)\end{array}$ & $\begin{array}{l}\text { LR-p } \\
(N=77)\end{array}$ & $\begin{array}{l}\text { LR-C } \\
(N=21)\end{array}$ & $\begin{array}{c}p \\
\text { (OR vs. LR-c) }\end{array}$ \\
\hline \multicolumn{5}{|l|}{$\begin{array}{l}\text { Distribution of pT3 / pT4 } \\
\text { cancers: }\end{array}$} \\
\hline pT3 $[n]:$ & 3126 & 70 & 17 & 0.173 \\
\hline pT4 [n]: & 270 & 7 & 4 & \\
\hline \multicolumn{5}{|l|}{$\begin{array}{l}\text { Distribution of tumor } \\
\text { locations }[n] \text { : }\end{array}$} \\
\hline Caecum / ascending colon: & 1144 & 19 & 2 & \\
\hline Hepatic flexure: & 304 & 3 & - & \\
\hline Transverse colon: & 285 & 3 & - & 0.004 \\
\hline Splenic flexure: & 171 & 1 & 1 & \\
\hline Descending colon: & 202 & 4 & 1 & \\
\hline Sigmoid colon: & 1290 & 47 & 17 & \\
\hline
\end{tabular}




\section{Captions for figures}

Figure 1 Conversion rates in the various colon sections.

Figure 2 Comparison of DFS in UICC stages I - III between the OR and LR-ITT groups (A) and between OR, LR-p and LR-c groups (B).

Figure 3 Comparison of DFS in UICC stage II between the OR and LR-ITT groups (A) and between OR, LR-p and LR-c groups (B). 


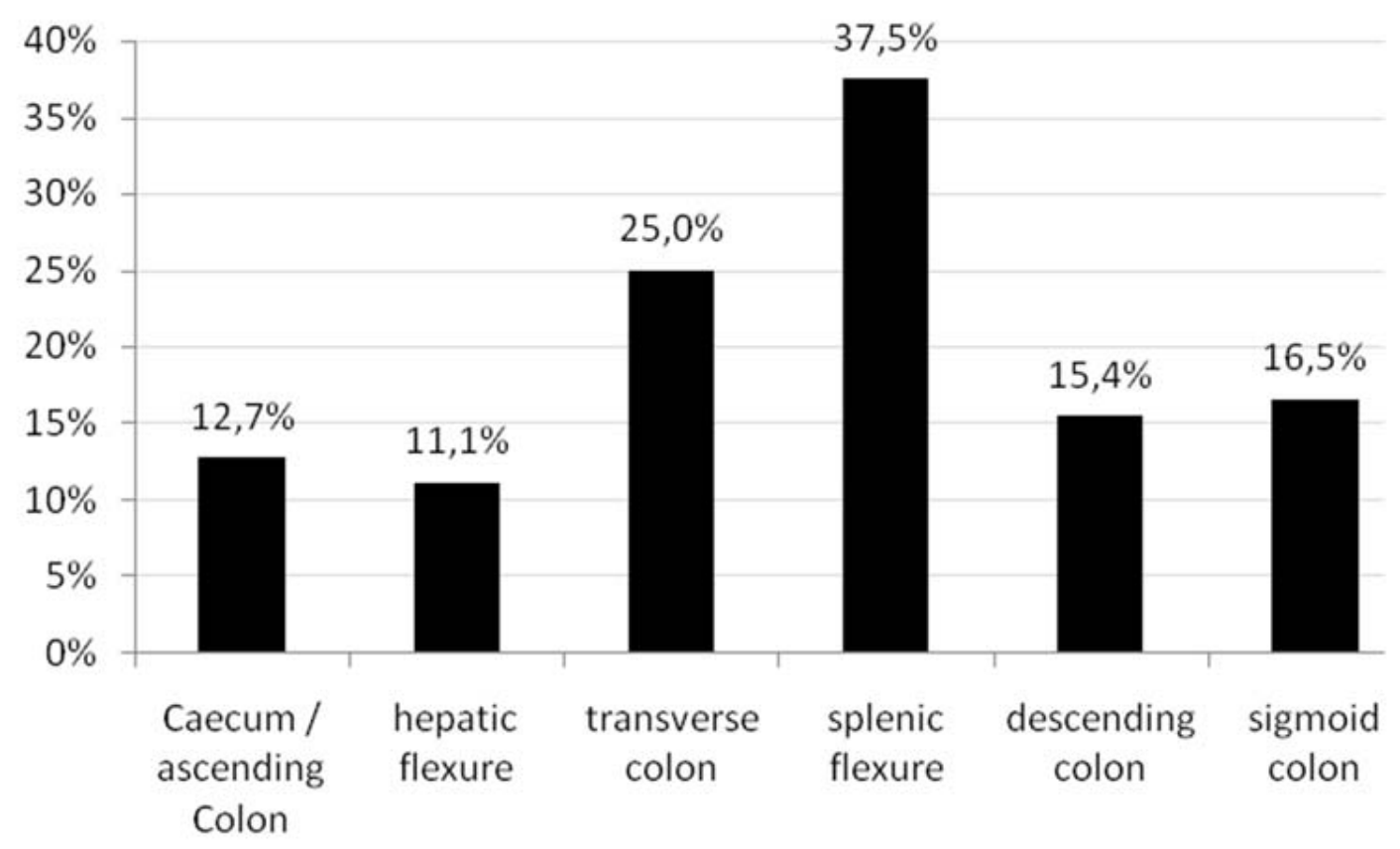



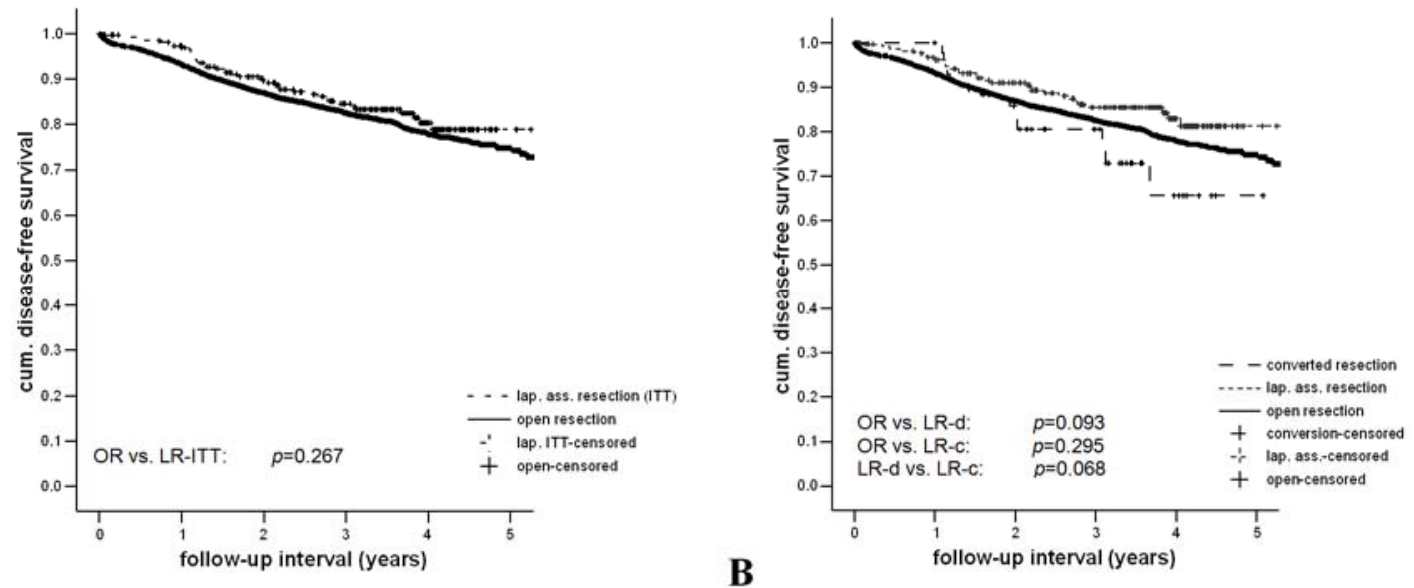

A

B 

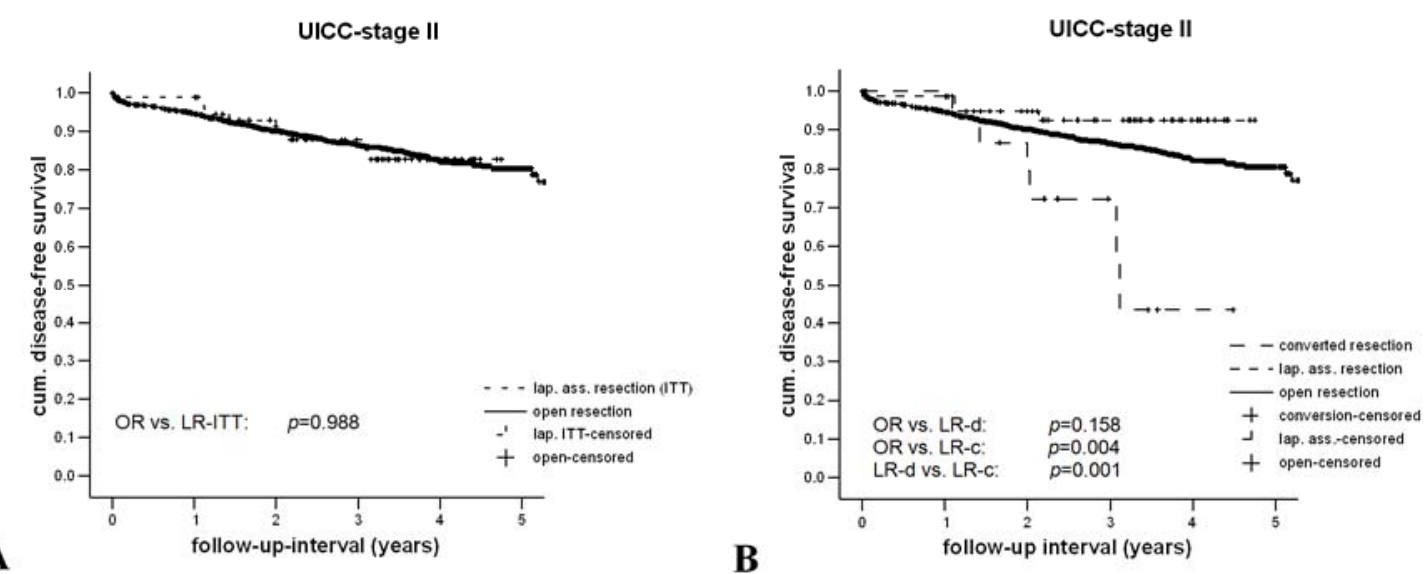

B 